Chng Huang Hoon, NATIONAL UNIVERSITY OF SINGAPORE, pvochh@nus.edu.sg Elizabeth Minnich, ASSOCIATION OF AMERICAN COLLEGES AND UNIVERSITIES, elizminn@gmail.com John Draeger, UNIVERSITY AT BUFFALO, draegejd@buffalostate.edu Johan Geertsema, NATIONAL UNIVERSITY OF SINGAPORE, cdthead@nus.edu.sg

Torgny Roxå,LUND UNIVERSITY, Torgny.roxa@lth.lu.se

\title{
In Conversation with Elizabeth Minnich
}

\author{
KEYWORDS \\ thoughtfulness, thinking, intensive and extensive SoTL, outcomes-based teaching and \\ learning
}

\section{PROLOGUE}

At the conference of the International Society for the Scholarship of Teaching and Learning (ISSOTL) in Bergen, Norway (October 2018), we were privileged to have heard a lecture by Elizabeth Minnich, "People who are not thinking are capable of anything: What are students learning, how are students learning it, and does it make them better people?"

In November 2018, as a follow-up to the lecture, Chng Huang Hoon (then ISSOTL vice president, Asia Pacific) invited the ISSOTL community to pose the questions to Professor Minnich. Questions from four members-John Draeger, Torgny Roxå, Johan Geertsema, and Chng Huang Hoon-were received. Professor Minnich emailed her responses to each question, and over the next six months there ensued several email exchanges between each contributor and Professor Minnich, which resulted in the first draft of this conversation. With the help of the above contributors, Huang Hoon wove the separate pairs of exchanges into this conversation, which not only addresses points in her keynote in Bergen but also discusses issues in her works.

Teaching \& Learning Inquiry has generously provided this platform for sharing the conversation. We hope TLI readers will benefit from this effort and we welcome readers to continue the discussion.

\section{CONTEXT}

We began with the crucial distinction that Minnich makes between intensive and extensive evil.

\section{Elizabeth Minnich (EM)}

As context, a glimpse of the distinction I made in The evil of banality: On the life and death importance of thinking (2017) in which I asked, "How could they do it? How do we do it?" These questions are hard to avoid when studying historical phenomena of horrific harm doing such as genocide 
and slavery as I had been. I found it illuminating to distinguish between, for example, genocide and a cult murder. I call the former extensive, the latter, intensive evils. Extensive evils and good are those that take time and many, many people to do their work. They cannot happen at all if only a few are animated to do them: you simply cannot murder a whole race of people or base an economy on chattel slavery if you have to rely on perpetrators who are possessed by hatred every single day for years, nor can there be effective resistance if you have to rely on a few heroic souls willing to be martyrs.

Extensive good or extensive evil each requires, then, reliable workers who can do horrific or wonderful work daily, as the normalized, ordinary thing to do, while intensive is done by anything but normalized, ordinary people. "Monsters" do intensive evil; "saints" do intensive good—and there are not enough of either to do extensive good or evil.

Or extensive is horizontal: it extends, reaches out, continues. Intensive is vertical: it interrupts the ordinary, goes higher or lower, deeper.

Other than giving some descriptive clarity-always crucial for research — the distinction has proven useful for understanding, thence providing at least some improved ability to diagnose toward the end of acting (I do hope) more effectively. In short, it helps me realize that one of our errors in trying to comprehend "the unthinkable" is that we are so strongly tempted to think of the reliable workers of extensive good or evil as alien to our ordinary selves and lives, far worse or far better. And that, I fear, may be the case for the doers of intensive good or evil, but it is not for the enablers and perpetrators of extensive events - not because "we are all little Eichmanns," which is not true, but because the ordinary can over time be shifted such that what once horrified or daunted many is normalized. We need, I think, to be attentive to the ordinary - the usual extensive, instead of taking it for granted.

As an educator and moral philosopher, this seems to me very important indeed. I doubt if we can educate against, or for, those who are morally extraordinary, whether in saintly or monstrous mode, but surely it is our calling to educate for simple clarity of thought and conscience in ordinary life.

\section{PART ONE: THOUGHTFULNESS, THOUGHTLESSNESS, THINKING AND TEACHING}

\section{John Draeger (JD)}

Your book The evil of banality powerfully articulates the harms associated with ordinary people living on thoughtlessness autopilot. However, I am less clear about what it might mean to be thoughtful. What are the features of a thoughtful person capable of

How we relate to our students, how we do and do not interweave their relations with each other in our classes, seem to me to be enactments of our own moral ways of being and also, whether we think about this or not, of those ways of being with others and the world that characterize our profession as teachers and also our disciplines. To teach in a certain way is implicitly to say to students, "This is the way a good teacher and a good (scientist, artist, engineer, whatever) treats others. That is, as teachers of something, like it or not, we are exemplars.

—Elizabeth Minnich forestalling harm? The village of Le Chambon represents a case of individuals having the wherewithal to engage in collective action that defied conventional authority and saved lives. 


\section{EM}

Well, not the "conventional" authority they chose as a community to accept, nor the "conventional" authority of their Protestant (in Catholic France) faith via their pastors, but certainly the imposed authority of the Vichy French and the Nazis which was actually not "conventional" for the villagers at all: quite the contrary.

\section{JD}

Even so, I wonder how the villagers were guided to goodness. Is it, for example, that they were willing to draw a line in the sand and say "I will not stand for this! Respect for humankind demands that I not be silent"? If so, then it seems that their behavior is consistent with people acting on autopilot, albeit an autopilot directed toward the good.

\section{EM}

Yes, I see that, and do think there is a banality of good as well as of evil. It is a question for more thoroughgoing history (see Caroline Moorehead's [2015] work about these resistant Protestant villagers) whether, when, to what extent it may be apt to say that some resisters really were thoughtless in their goodness.

Thus far in my reading, I would want to say that most of the good people had to begin thinking, whether or not they had been doing so, rather quickly because they had to deal with each new situation as it arose and act well enough to save their "guests" as well as themselves and their own families. I might say that few if any had the luxury of being thoughtlessly good in such times. When tested, they were quick, inventive, effective. But as I said, I take your point and am watching for it.

\section{JD}

Did the villagers wrestle with important concepts (e.g., justice, respect) in open and flexible dialogue with others members of their community?

\section{EM}

It seems to have varied. Some, like those in Pastor Trocme's church, did; others, maybe less so (although Trocme himself was sometimes said to be rather, shall we say, forceful).

JD

How far does open questioning extend? For example, could openness include questioning the value and dignity of the human person?

\section{EM}

I myself would think so. How else to deal with the question of whether to lie, to resist, even perhaps harm (even kill) those who would otherwise harm the children in one's care (for a common example)? How to deal with the issue of pacifism, when it is the Nazis against whom one stands? There is a fair amount of evidence that those who resisted variously struggled with just that question: are they, 
the dangerous ones, the killers, also to be accorded treatment as valuable human persons? How then resist, lie, even kill? To come to seeing all as equally to be valued and so protected: that is a challenge we see throughout these stories, this literature, and it comes often as a story in which one who would value and protect the killers must stand against, even put at risk, those the killer has targeted.

\section{JD}

I am pleased to hear that the villagers struggled, at least some of the time, in their deliberations. I am pleased because their struggle suggests that they weren't working on autopilot that happened to be directed at the good and because it suggests that they weren't freakish moral saints. Rather, the picture you paint suggests that they, like the rest of us, are moral works in progress who must bumble our way through difficult situations and dig deep for the wherewithal to do the right thing.

Are abstractions always negative?

\section{EM}

Of course not. We could not think or speak beyond an early infant level without them.

\section{JD}

I agree that many gross generalizations about particular groups of people are both inaccurate and destructive.

\section{EM}

These are faulty generalizations (see my book, Transforming knowledge [2005]).

\section{JD}

I further agree that we ought to be concerned with the particular individuals in front of us and not the nameless, faceless, vaguely undifferentiated “other." However, I also think that important values, like respect and fairness, constitute positive abstractions point to visions of a better world. While positive abstractions also need to be concerned with the individuals in front of us (e.g., what this particular person in front of us deserves given the circumstances), it seems to me that affirming the transcendent dignity of all human beings is an abstraction that has the power to guide both individual choices and social movements. Would you agree?

\section{EM}

Yes, these are principles, horizonal values. And yes, as what I would call horizonal values they are ones that challenge us to deal with the searing questions of how to protect ourselves and others against those who themselves violate just those principles not abstractly but really-those who dominate, oppress, torture, rape, kill. You are hearing the degree to which I think pacifism is an extraordinary achievement requiring both moral and political strategy, not only an abstract issue of principle. 


\section{JD}

If so, then being thoughtful would involve both avoiding negative abstractions and discovering positive ones.

\section{EM}

Yes, I would say avoiding faulty generalizations in favor of more sound ones, but always with awareness that we do not and cannot know enough, that there is change as well as difference in this world, and that therefore attentiveness and the ability to be startled back into thought are crucialwhether we are otherwise working with "negative" or "positive" abstractions.

\section{JD}

I thank you for pointing me to your earlier work and the importance of horizonal values. I understand the objection to the evils of banality was leveled directly at faulty generalizations that allow for autopilot to go amuck.

As for positive abstractions, I think that we might be coming at a similar idea from different directions. I say that fundamental values, such as respect, justice, liberty, and personal well-being, are abstract because they are the sorts of things that are common to the human experience. As such, they have near-universal appeal in the ways that they transcend individual experience. At the same time, we need to consider how these values are lived out in the concrete experiences of particular people in particular circumstances. For example, it is easy to say that I respect the dignity of all people. It might be true at a certain level of abstraction, but the real question is whether I can acknowledge my privilege and recognize the historical significance of racism, sexism, and homophobia in order to act in ways that demonstrate respect for the particularly situated persons in front of me. I would argue that the big ideas (e.g., respect, justice) give people from various walks of life common anchor points for discussion, but the real question is how those values are lived out in everyday life.

\section{EM}

Thank you for these questions. They are crucial, and both familiar and ever new. In truth, it is not answers in which I place trust, for which I hope: it is the spirit of troubling, troubled thinking you have made manifest.

\section{Chng Huang Hoon (CHH)}

Picking up on the discussion mention of values and ethics, today's volatile, unpredictable, complex, and ambiguous world demands that we teach students how to think and negotiate ethically beyond the university curriculum. How do we teach without necessarily prescribing a certain manner of thinking? How do we infuse ethics and judgment in light of the onslaught of a rapidly changing world? What should teachers focus on the most? 


\section{EM}

A fine question, and one far too often avoided in higher education, so all the more important. I think it may be avoided at least in part because it seems that there is no way to avoid one of two options, both rightly worrisome. One option is to prescribe, as you put it, "a certain manner of thinking," which I suspect many people would understand to mean, "a certain moral or religious code." We cannot choose that option unless we are teaching in a religiously affiliated school or one that openly proclaims itself within one developed ethical tradition. The other, of course, is to claim "value neutrality," "objectivity," achieved by adherence to "scholarly norms and standards" for which "truth" and "soundness" are distinguished, and protected by method and validation, from "belief," "opinion," and "values" (such that values are implicitly assumed to be "merely" subjective).

I agree that nonaffiliated schools ought not teach any one religion or moral dogma as if it were unquestionably the true and right one. Of course not. I also agree that scholarly truth and the truths of religion or opinion are importantly different, and our business is with the former. But there are two dimensions of education missing from the usual oppositional framing: one, and to my mind the most important, is the thinking we practice with our students, both within and about subject matter; the other is the relations, the ways of being-with, we enact as teachers with our students and so also foster among students in our classes. Both of these, ways of thinking and ways of being-with, or relating, seem to me already morally significant, without the addition or absence of creed.

How we relate to our students, how we do and do not interweave their relations with each other in our classes, seem to me to be enactments of our own moral ways of being and also, whether we think about this or not, of those ways of being with others and the world that characterize our profession as teachers and also our discipline. To teach in a certain way is implicitly to say to students, "This is the way a good teacher and a good (scientist, artist, engineer, whatever) treats others." That is, as teachers of something, like it or not, we are exemplars.

May I say that there is work along those lines in The evil of banality and will be more in Thought work: Thinking, action, and the fate of the world (in press). Here for now is a bit more of what I can say in this restricted space.

\section{Thinking}

We can teach about and practice our students in the thinking that is characteristic of our fields, such as thinking like a lawyer, like a scientist, like a poet, like an engineer, or like a business person. That professionalized mode of thinking is very likely indeed to be said to be "morally neutral," with the hope then expressed that professionals will use it for good rather than ill. That is fine, up to a point, and better when we also discuss the ethics of our field (medical ethics, legal ethics, and the like, as well as research ethics and whatever else may be or could become relevant as considered in broad courses such as professional ethics). In truth, though, these important ethics courses seem to me at risk of being too little, too late, as long as what is actually taught as and about a field claims to be morally neutral and so not subject throughout to what I call internal questioning (e.g., of a field's central concepts, as in "What would change in this analysis if we defined collateral damage differently?" "What have been the effects of 
diagnosing people as bipolar rather than manic depressive, of removing homosexuality from the [Diagnostic and statistical manual of mental disorders] list of psychological disorders?)

That is, it seems important to me that we can also think with our students about the thinking they are learning how to do. We can explore with them what some kinds of study make hard to take into account; what kinds of relations a field assumes between and among people, issues, facts and values, and the like. We can ask why and how prevalent modes of reasoning and formative concepts within a field might or might not make it possible to be, say, a "good engineer" who as such need have no concern about whether it is work that a "good person" ought not do. This kind of internal exploration of our fields is not often done; it is a growing cause of mine to see if we can do it more, more often, better (which is what Thought work is about, as, in its way, is Transforming knowledge, a study of how fields continue old prejudicial exclusions and devaluations as a result of conceptual errors such that even entirely well-intentioned researchers can produce results that confirms those old errors).

Implicit in all that is what is key: we can think about our own (and others') thinking, and that means that we can also evaluate it as we do, or can, evaluate our actions in the world. If nothing else, we can, then, practice thinking about our own thinking, and the thinking in our fields, with our students and that is a way to awaken conscience, which, whatever its content, its norms, rules, creeds, is first a practice of being aware of — thinking about — what we are doing (or contemplating doing, or have been told to do-that is, not only actual actions). Practice reflexive, reflective awareness with students, and you will not give them right/wrong codes, but you may enhance their ability and increase the likelihood that they will think for themselves about what they are and are not, ought and ought not, be doing.

If we ought not only train or indoctrinate them-as, of course, we ought not if we are educators - what we can do, it seems to me, is practice becoming ever more thoughtful with them for everyone's sake. We will differ then about what is right or wrong, of course, but if those who differ are, again, thoughtful, we can at least go on talking and thinking together.

\section{Relating to our students}

This might even be obvious once we stop and think about it. The ways we treat our students and facilitate their relations with each other, and do or do not discuss the ways they, as professionals in our fields should they enter them, relate to others and to the earth. Of course we are teaching moral sensitivities and behavior (whatever formalized codes of morality may justify them; differing dogmas often turn out to advocate ways of behaving that are quite similar).

Many of us know and reflect on this important relational aspect of our work as educators; others, I fear, do not. As with thinking about our thinking with the students, this, too, could and ought, I believe, be made more conscious, and talked about among faculty and students. We need each other to do this well — and that, too, is a moral commitment, and, when we take it up, a kind of teaching.

As we can think about the thinking of our fields we can also think, and talk, about ways of being professional educators, teachers, professors (or any other professional sort). This is not unusual, but a fair amount of it can tend to confirm conventional notions rather than thinking them through. I am often startled by the ease with which professors say things about the effects of their ways of relating to their students that seem to me troubling although; (or maybe because) I hear them all the time, which makes 
me suspect that somehow they have come to seem "professorial," characteristic of a good teacher. For example, "I shake them up, but that's good." "You have to be made uncomfortable to learn, to get out of your comfort zone, your assumptions." Such statements are usually met with nods: Yes, that's one of the strengths, and burdens, of a good teacher. So I then want to say, "Can we think about that?" Unfortunately, it seems to me an attitude, a way of behaving, that can suggest to students a lack of respect for their own thoughts, beliefs, values. And that lack of respect, here for something as intimate to people as values, can license (and serve as an excuse or rationalization for) an unnecessary roughness from an authority figure due perhaps to no more than a lack of skill in drawing people out as distinct from challenging, grilling, arguing with them. Might we not do better questioning them thoughtfully, trying to earn their trust that it is enlightenment and mutual respect we seek? We are practicing and therefore also teaching ways of relating that have political effects as we teach, too, no?

There is another crucial topic here that I will simply gesture toward for now: Can there, ought there, be equality in a classroom? What is the most fruitful mode, or modes, of relation specific to education? How do such modes relate, distinguish, separate education from other kinds of relation into which students will enter when graduated? Education is neither morally nor politically neutral. I repeat: students learn about authority, power, equality, mutual respect, dominance and submission, obedience and independence and more as we teach and learn together. I really do think it is a failure of responsibility not to think together about that: pretending it isn't happening does not, we do all know, make something go away. The field of Scholarship of Teaching and Learning is well prepared to continue inviting educators to be ever more responsibly thoughtful about the future world that is already present when and as we teach and learn together.

\section{PART TWO: THOUGHTLESSNESS, SCHOLARLY REFLECTION, AND OUTCOMES-BASED TEACHING AND LEARNING}

\section{Johan Geertsema (JG)}

In The evil of banality, you criticize an outcomes focus, also and in particular with regard to education, for example when you write that "we can also suffer from

I tend to believe that teachers should teach as each does best, creating through the years their own most authentic and honed art. Some are superb lecturers, and that's a high art; some are brilliant with discussion; some mix modes; some flourish with engaged, active, experiential teaching; some use multimedia, and so on. I like that immensely: if we believe that every learner is unique, why on earth would we try to fit teachers into any one mode as if we were all the same?

_Elizabeth Minnich pedagogies that stress 'outcomes' rather than the process and practice of thinking" (Minnich, 2017, p. 114). Could you elaborate on why you think an outcomesbased approach to education is problematic?

\section{EM}

I do so for several reasons I can only sketch here, so please excuse the un-nuanced statements, and just a few points. Read them as markers that should be discussed from many positions.

- In general, it is my observation that putting too much, let alone all, emphasis on outcomes virtually guarantees some kind of corruption. How not, if only the ends 
matter, and not how those ends are achieved? Schools that lose funding based on their students' standardized test scores will find ways to get those scores up. In the United States, we've had cheating scandals, and in some ways still worse, we've seen schools find ways to get rid of the students they are sure will pull their overall scores down. Reward and punish based only on results, and you'll need a lot of gimmickry to counterbalance what you have said structurally: we don't care how you get there, just get there. What kind of lesson is that for students, future citizens, business people, politicians?

- It is not unavoidable but nonetheless far too common for specification of "outcomes" to be reductive as people try to come up with something that can be clearly and easily observed and evaluated. Nothing wrong with that, except - big except-when the outcome then given is so unambiguous and so delimited that reaching it through an honestly explorative inquiry engaged in by differing individuals becomes very difficult indeed. This may not corrupt the process, as I said first, but it can lead to manipulative teaching, particularly in what are supposed to be discussion classes. To avoid thus falsifying inquiry, there is then a temptation to make the "outcomes" sound great but be terminally vague. Fine in one sense; most inquiries and explorations have some sort of notion of what might satisfy them, tell them when they have concluded. But in truth what I think happens is that many faculty just go through the motions, coming up with something that sounds acceptable for those requiring these things but is indeed so vague that it won't cause problems. Waste of time, in short, and invitation to a kind of hypocrisy of which we do not need more in this world.

- If we could have the time, money, and brain work that has gone into the outcomes movement (whatever you call it), think what we could do.

- It does not impress me that when academia is called on to do something sensible and just - like undoing prejudicial exclusions wherever they are, or in this case, being responsible for claims it makes - what we do is add on all sorts of stuff. What was called for was all of us doing better in a specific and important regard; what we do is add bureaucracy and spend money getting other people to do it for us-or find ways to make us do it. Not the way to transform for the better, in my view.

- And quantitative measurement is too precise to be accurate for some things, experiences, meanings, which can make it, apparently but not really paradoxically, far too imprecise to be useful. Or harmful: a precise quantitative measure of the cost of manufacturing a drug held against a precise count of the number of people whose lives it could save can lead to the "rational" calculation of cost/benefit that writes off the toofew who will die in the case of an expensive drug for a relatively few children. I know that's familiar and stark - if unfortunately an actual kind of example, but it does make vividly clear how making decisions among abstractions such as numbers alone, or as decisive, or even as heavily weighted, can — need not, but can and has-allowed people to make decisions and live with them because they are protected from realities by 
calculations. Yes, lives are saved through precise engineering and scientific calculations. It is an imbalance we fear, not quantitative measures or precision, and inappropriateness, as always.

- Education should be intensely interested in the unique, not only or inappropriately with the strictly comparable (unless or except when rising generations have come to be seen, or are wanted to be, literally nothing more or other than replacements for those leaving life, or fillers of predetermined slots). What measurement does is reduce things to one common expression - a number, usually_-so that more and less can be calibrated without ambiguity. More and less intelligent is a very tricky judgment (think how many ways minds move, and can move well); more and less intelligent is not tricky when "intelligence" has been expressed numerically: 140 is simply more than 90 . If "intelligence" were an attribute with no serious consequences, that might not matter: need I say, "but ...."?

\section{JG}

Perhaps in part because of the focus on measurable outcomes, higher education is increasingly becoming subject to an instrumental, and in your terms, banal focus on mastery understood as "offering preset ways of processing experiences of the world, of the self, of others" (Minnich, 2017, p. 216). This is apparent in a view that tends to reduce it to training, and that approaches curriculum as only in need of being "constructively aligned" - that is, oriented toward achieving measurable learning outcomes through instrumentally conceived learning experiences, so to the exclusion of interrogating the values underpinning those outcomes (Dunne, 1993). This view of higher education, in its instrumentalist approach and exclusion of praxis, runs the risk of resulting in the kind of thoughtlessness that you describe as necessary for extensive evil. I understand praxis here as indicating ethical values and as distinct from poiesis — "the activity of producing outcomes" (Dunne, 1993, introduction) —and technical knowledge. Aristotle sees praxis as another type of activity conducted "in a public space with others in which a person, without ulterior purpose ... acts in such a way as to realize excellences that he has come to appreciate in his community as constitutive of a worthwhile way of life" (Dunne, 1993, introduction). It is a view of higher education fixated on techne, and it runs the risk of training people to become technicians who lack morality, resulting in "good" engineers who, like Eichmann, become bad engineers.

How can we who work in higher education counteract and subvert this widespread and potentially dangerous dogma? How might the scholarship of teaching and learning movement, with its emphasis on reflective practice and inquiry into student learning, assist in this endeavor by fostering an ethic of care?

\section{EM}

Thank you, Johan. Your second sentence just above seems to me a response (or an opening to a response) to the question posed in the first sentence. If that's right, then what is on your mind as a follow-up question, interest, concern? 


\section{JG}

What is on my mind here is that SoTL is increasingly becoming an instrument for promotion and the professionalization of teaching in higher education. I worry that SoTL itself could become part of the problem with outcomes-based education in precisely reinforcing an instrumentalist approach to education, by compelling academics and others who support learning to demonstrate measurable outcomes of their students' learning, necessitated by SoTL's becoming merely an instrument for promotion and the professionalization of teaching in higher education. How do we resist the danger that unwittingly it may reduce teaching to mere "professional proficiency in techniques" (Minnich, 2017, p. 211) as measurable indicators of excellence?

\section{EM}

Do you think that reflective practice can be transmuted into measurable proficiency in techniques and still be reflective practice? Behind that, I realize I am also asking if there is a catch-22 in the situation you question - that is, that some take up SoTL as research that they want, need, hope will indeed help them keep their jobs and get promotions and so, insofar as their field requires it, treat teaching and learning as something to be studied and evaluated in ways that may not always be appropriate to it (or perhaps to your and some others' thoughts about what is appropriate?).

Do you know about evaluation as a field? I'm thinking of Michael Q. Patton's books. Evaluation professionals have been facing similar questions: how to produce studies deemed acceptable by "rigorous" and also very narrow standards without ignoring other crucial questions — such as worth and values, consequences, help or harm - that are often defined as outside the boundaries of a project. Patton's work $(2008,2014 ; 2015)$ refusing the conflation of "sound" with research methods that turn all into the measurable and so strictly (but often inaccurately) comparable could be of use to those in the field of SoTL who are concerned with the nexus between research and evaluation of teaching.

\section{JG}

Most fundamentally, I am concerned about what I perceive as an overwhelming focus on intended learning outcomes or goals in higher education, a focus that marginalizes questions of value, that sees an educator's task as essentially consisting of devising learning goals, assessing whether students have met those goals, and aligning the pre-set goals and assessments with teaching strategies but leaves un-thought the rationale of the goals and presupposes the value of these goals. It all threatens to become a very mechanical, procedural system that emphasizes technique and skill at the expense of larger questions of values and rationale, not to mention ethical and political issues. I notice this procedural approach everywhere - in faculty development, in classroom teaching, in promotion policies, in curriculum policy and governance meetings — and I want to underscore that these observations are by no means limited to the university where I work.

Second, I am further concerned that SoTL might model and in fact, perhaps unwittingly, encourage this procedural emphasis as it increasingly becomes an instrument for promotion, a means for evaluating teaching quality: essentially, a means of checking whether educators devise goals, assess those 
goals, and align all of this with teaching strategies, which they then need to demonstrate and document in order to be rewarded, once again marginalizing values.

So, a follow-up question, is really the very practical issue of how we can think of SoTL's inquiry into student learning as opening up dialogic spaces of care, hence an ethic of care. Of course, this practical issue, as you say, has different dimensions. Strategically, how do we position SoTL within the university in order for it to function in a way that fosters an ethic of care?

\section{EM}

Still sorting out different kinds of questions here:

1. How, in terms of governance and the like, to protect and enhance the chances of those who study and value teaching and learning to practice what they believe in and to influence others - or even the ethos, policies, and practices of the whole institution? To be genuinely, directly helpful, this one would require analysis of a present real situation on the ground in particular circumstances, as useful strategy that can lead to effective tactics does. I have been various kinds of administrator too long and in too many roles ever to overlook the need to analyze what's blocking desired change in this institution, here and now. General theories of institutional change are useful to have in mind, but each situation has its own blocks, levers, and the like—as, of course, you know.

On a more general but neither theoretical nor formulaic level: those active in SoTL might move to be on decision-making committees; continue striving to be exemplars in their own work; mentor new faculty; sponsor small, informal, but regularly scheduled discussions, perhaps over a meal or coffee or tea once a month, about teaching and learning, to which individuals not involved in SoTL are personally invited; sponsor open discussions with speakers from inside or outside, relating teaching and learning to pressing present issues (free speech comes to mind for those in the United States just now, for example); work with bookstores and libraries to do special displays; put together their own "advisory council" with members who are both good colleagues and influential outside of the college or university. Changing a culture so that systems and individual practices change means working on all levels, doesn't it? Local analysis identifies which are most effective as the effort continues.

2. What are the theoretical underpinnings for how an ethic of care might relate to reflective practice?

In my experience, inviting others to discover the intellectual depth, range, and interest of what they may think of - and turn away from as - on-the-ground change in practices is very, very important, particularly in academia. Even if what you want to get to is the articulation between an ethics of care and reflective practice (which you are convinced is there), for both intellectual and strategic reasons, I would suggest also separating ethics of care from practice in teaching in order to discuss it, drawing in philosophers, political and legal theorists, and the like (I say a bit about this issue below, in response to Torgny, but along different lines below.)

JG

Could you say a bit more about how you think I could as a teacher open spaces of inquiry and care? 


\section{EM}

Are you asking for techniques? I imagine, again, that you and SoTL and other resources can be drawn on readily. I guess I start from Plato's Socrates and Socrates' Diotima; consult John Dewey, William James, Jane Addams, W. E. B. Du Bois, Anna Julia Cooper; engage variously with Hannah Arendt's 1971 lecture “Thinking and moral considerations” (see Arendt, 2003) and Karl Jaspers's Question of German guilt (1947) (but it's a crowded room, the one with my thinking friends on teaching). For teaching practices, I'd have to confess that I like to read Sylvia Ashton Warner, Vivian Gussin Paley, Eleanor Duckworth — teachers of teachers of young children-most of all, although I do love William James's lecture "Talks for teachers on psychology and to students on some of life's ideals" (1992), too. But I think you said you've read my articles “Teaching thinking” (Minnich, 2010) and "Present teaching” (Minnich, Sorkin, \& Gardner, 2016; see also Minnich, Gardner, \& Sorkin, 2016), so you know I don't have any one theory to apply.

I tend to believe that teachers should teach as each does best, creating through the years their own most authentic and honed art. Some are superb lecturers, and that's a high art; some are brilliant with discussion; some mix modes; some flourish with engaged, active, experiential teaching; some use multimedia; and so on. I like that immensely: if we believe that every learner is unique, why on earth would we try to fit teachers into any one mode as if we were all the same? (I don't even believe in "best practices." Best for whom? For which subjects, in which situations, for which students, for which time of day and weather, and shape of classroom, and state of fear and anxiety of the students?).

I know people whose lectures, very different as they are from each others', open spaces for thinking - which I agree is something we do want to try artfully to do. On a large and deep scale, there are the likes of these: Karl Jaspers's Question of German guilt (1947) lectures given in Germany very shortly after the end of World War II-very brave and difficult and challenging invitation to all concerned to reflect where and as it is hardest; Martin Buber's lectures and essays; James Baldwin; Toni Morrison; Hannah Arendt. You will have your own list, as do others.) Arendt was not good at discussion, but thought aloud as she lectured. I have heard that John Dewey did the same often - just thought out loud-so we got to listen in. I wouldn't want that interrupted, the train of such thought derailed.

I start with defending lectures, I think, because most of the people with whom I find myself educationally compatible tend to dismiss them as if it were the mode rather than failures of skill that were entirely at fault (true enough that there are many boring to awful lecturers, an outrage to the gift of attention, I agree). I guess that in truth, along with recognizing how different every teacher as well as every learner is and so avoiding standardization whenever possible, what I believe in and seek most is questioning. Simplistic version: you don't understand the answer if you don't understand the question. You also don't care about the answer if you haven't been engaged, animated, interested by the question.

When I remember discussion and other kinds of classes and what made me feel as if I had done badly (or, when observing, made me uncomfortable with someone else's teaching), what I find is some variant of the following: I answered a question no one had raised or cared about; I answered a question as if I was immediately certain what that individual wanted to be asking. Neither shows real interest in 
and care for either the student or the subject, I think. Or I asked lousy questions (happens often: I make lists of opening questions for every class, choosing one as the sense of the group makes itself felt. Still practicing). Or I asked a fill-in-the-blank question ("When did the First World War start?") or a do-youknow-this test-like question ("What does categorical imperative mean?"). Or I asked a far too big question ("Why are there wars?"- maybe okay to start with, but needs to be followed by an engaging, possible, smaller question — maybe, "Do you think there are wars because men just like to kill?" — not a good question but one that I've found people have opinions about, so that's a start). Students teach us when we've become good at asking questions - many more of them are interested enough to want to respond, not just the Good Student.

To be interested - to be/est between/inter-is to live open to just about anything and anyone. But there's too much to say here, too, of course. It would just be ongoing fun to talk with teachers and students about questioning, trading examples of what we think were good ones, awful ones, fruitful ones, sneaky ones, manipulative ones, nasty ones, aggressive ones.

JG

How do we as universities open such spaces for faculty to approach their teaching not only in order to meet pre-set learning goals?

\section{EM}

It occurs to me here first to observe that these are not even learning goals. They are knowing goals (which are evidently important but not the same-as professors in, say, law school tell students that they are learning how to "think like a lawyer," more importantly than trying to learn what lawyers know). Might get lots of impressive people to come talk about what is really useful in their work and in their lives.

You have a rich and specific notion of what praxis means here, evidently, so I hesitate to join in without more questioning to help me engage with those meanings. Without that, I find myself thinking of Richard Bernstein's still-brilliant book, Praxis and action (1999), which doesn't help me locate your meaning, being an exploration of these terms through several schools of thought.

Could we say that "reflecting on larger meanings and rationales" could be done as an extremely effective way to elucidate and interest students in coming to know, via processes of thinking, questioning, discussing with diverse others, exploring contexts? That is, not as a replacement, but as an enrichment, as it were? Or would you want to propose it as a replacement, implementing a fully developed pedagogy (Paulo Freire, perhaps; Henry Giroux; people like those in May and Sleeter's (2010) anthology?) So far, I'm more interested in the former, always reflecting around and about whatever we are studying together, so I lean toward practicing questioning, and listening, remembering contexts, exploring connections. 
PART THREE: INTENSIVE AND EXTENSIVE SOTL

\section{Torgny Roxå (TR)}

I am mostly interested in the terminology, intensive and extensive that was used to discuss evil and good. In my own keynote at ISSOTL in Bergen (Roxå, 2018), I used the same terminology in relation to SoTL: intensive SoTL would mean defined SoTL projects (sometimes with money, sometimes even close to educational actions research projects), while extensive SoTL is an attitude that permeates everyday life and its interactions. I am seeking feedback on this idea of intensive and extensive (used for two specific aspects of life) as used on other aspects of life, such as how we, in our everyday life, with its almost infinite number of daily interactions, talk and act in relation to teaching students.

\section{EM}

A very interesting possibility, and if it turns out to be illuminating-even should the distinction take on differing aspects and meanings through this use-why not? So, let me see what happens as I think it through a bit. SoTL as intensive, for projects, research: To me, that would mean that these are bounded, time-limited, extra-ordinary undertakings that involve few people, however wide their reputation and influence might sometimes be. Yes, I see that as useful as well as coherent with and likely to add nuance and range.

To try it out a bit more: These would be projects undertaken by one, a few, or a demarcated group of people that are, as I said, extra-ordinary: to do a project is to step out of what we do with the unselfconsciousness of those who already know how to ride the bike, as it were. We step back from the just-doing to learn and perhaps do something about it in a more or less formalized mode, but intensely, intently, with intent, such that our intentions themselves become of interest-to play with intensive, obviously. Such bounded events are vertical, in my too neat graphic image, to the horizontal ordinary that precedes and will succeed them. And then I think about how this can be of value, as when we stop, and think, and then return to renew the ordinary ("The most notable distinction between living and inanimate things is that the former maintain themselves by renewal" [Dewey, 1944] is the opening line of a book not about nature, as you no doubt know, but about democracy and education.)

I like this: among other things, it invites fresh reflection about what we are actually doing when we undertake research or related projects, and that is surely both healthy and interesting. In focusing us on what we are intentionally doing (not only in the highly focused terms of the project itself, but taking the doing of a project to be already of interest), it also opens the space for moral and political considerations. Not as external considerations, but as these are internal to choosing to do something. 
That's where I go now in part because I do not hold that methods - the how of doing something — can accurately, or safely, be considered neutral as merely instrumental. However varied the reasons for such a view, we have research ethics review boards everywhere now, so I am at least on that level hardly alone. Anticipating the distinction, I might then note that it is not unusual for people to accept bounded, specific regulations and rules of research ethics while not wanting anything like that for our daily, ordinary interactions as teachers. (The long footnote I won't write here would explore differences among rules for ethical research; professional ethics; general societal mores - that is, differences along a continuum from intensive through int/ext/professional to extensive.)

Obvious need to think such things through carefully: I think that points up key differences between the intensive - purposeful, defined, bounded, short-term, extra-ordinary, done by an identified one or few, and the extensive. To judge the intensive is possible without sitting in judgment on a lasting, normalized way of life involving many, many people. That should remind us to pay attention to important differences between intensive and extensive, even as we also compare and look for, perhaps work for, more or less coherence of particular sorts. And still, how I treat research subjects and how I treat students ordinarily are distinguishable enough to raise questions that could be useful about both, particularly when research is intended to be for the sake of students.

I would then ask what more, else, or other is illuminated by casting light with this distinction on such aspects of projects, and the like. What do we thus point up so we can see more clearly, and what then might we become better able to think well—or at least afresh, hopefully usefully—about that otherwise can be missed or just sort of passed over?

Then, SoTL as extensive, about which you said, "how we, in our everyday life, with its almost infinite number of daily interactions, talk and act in relation to teaching students": You give us neatly something very basic and existentially grounding about everyday life, and then a specification, "teaching students." That tension between basic givens and specific arena gives us from the beginning a need to ask about their coherence or lack thereof. But your initial general/particular distinction could also suggest some questions that are different from those raised by reflecting about intensive and extensive. I cannot begin to think that through now, but it will help; thank you.

I think I'll try this now: Teaching as a profession is not in usual senses a project; it is purposeful, but it is also extensive. It has boundaries, but, as long as we speak of education rather than training or indoctrination, it is not controlled and made uniform by them. And for SoTL, teaching is extensive as the teaching profession is in general, but it is also intensive in another sense: it is, taken all together, also committed to some openly stated values it is its purpose to realize. All of SoTL is in that sense a project. So, SoTL has a doubled, or reflexive, or perhaps meta-, dimension relevant to projects it and its members do that are intensive, such that_-perhaps? - it is of interest and maybe concern whether intensive projects are coherent with the extensive project of a purposeful, value-committed organization.

Intensive projects subtended by SoTL as extensive project, the overall purpose of which is extensive good, by which ordinary, daily, common decency has become unremarkable: I like that, of course, and particularly that the uses of extensive keep the values in play from becoming, excuse me, intensive, vertical to the horizontal lives we, the many, live in our real, plural, changing, messy ordinary world. 
Most important to me is that you use extensive SoTL to raise the crucial question of the relation of what we do as teachers (as I want to raise it in any kind of work) to who and how we are as we lead our ordinary lives, and vice versa. This invites us out of the kind of enclosed thinking (from personal compartmentalization to professional jargon to normalized society-wide racism, say) that disables conscience, judgment, choice, and so, moral responsibility).

For my next book, a collaborative anthology with Michael Q. Patton (in press), this is just what we asked our contributors to reflect on. We have no answers, of course; we are just hoping to raise and find effective ways to think together about the meaning of good in a good person in relation to and in distinction from the meaning of good in a good teacher (or lawyer, business person, economist, grassroots organizer, and so on). This is why I found myself just now over-focusing on how intensive/extensive may help us think better about differing arenas in relation to moral political judgments.

More specifically regarding research, among research projects, it seems to me we can use the distinction as well. Some - the intensive-are characterized by great concern with achieving precision, which, it might then be noted, can require very careful controls on all levels (unambiguous definitions, few variables, narrow focus, and the like). All that, I will say, interrupts and is meant to interrupt the flow of experience, the ordinary.

Extensive research projects, on the contrary, would then be those that are calibrated to illuminate something about that flow of experience as it actually is - widespread, continuing, changing, multiplicitous, interweaving all sorts of transactional relations (as you put it).

We can, then, confuse the appropriate precision of intensive studies with the appropriate accuracy desirable in extensive research. We can also unfortunately value precision over accuracy; or become sloppy about accuracy because, not aiming for precision, we think almost anything goes. Sorry: a bit too much elaboration for this exchange, but obviously this interests me and seems important regarding research that will have real world effects.

I have also in mind here the question Johan poses above: "As SoTL increasingly becomes an instrument for promotion and the professionalization of teaching in higher education, how might we resist the danger that unwittingly it may reduce teaching to mere 'professional proficiency in techniques' ... as measurable indicators of excellence?” Avoid privileging intensive research, I might say, and keep the conversation and reflection about the relations of intensive and extensive SoTL going. For example: If SoTL is both extensive-concerning how we live and have our being; and more particularly, as it concerns a profession - it has values and commitments, an ethos, norms and mores as lasting, chosen communities such as professions do. Insofar as that is the case, SoTL might need to consider carefully what kinds of projects it ought to release into the world for its use, as Johann's question may suggest. So might any profession: methods are not neutral, and being appropriate is an oft-overlooked but, to my mind, crucial moral and political, as well as epistemological, value.

As Johan also observed along these lines, surely there is coherence between reflective practice and an ethic of care. The latter, it seems to me, can be seen as an ethos with and toward which we work in the hope that it can become an extensive good — that is, lasting_-done by many people for whom it is just the ordinary way to be, barely even seeming normative anymore. A question then is whether, or how, the former, reflective practice, articulates in mutually renewing ways with the latter. That is, I 
wouldn't see reflective practice as a means or method that takes us to the end of living by care ethics but, rather, hold a close-in practice in conversation with a horizontal purpose such that both remain responsive to what we keep learning. SoTL as extensive project.

I think your use of the distinction also works descriptively on a more basic level you evidently surmised (thank you). First, daily life is filled, as you say, "with its almost infinite number of interactions, talk and act[ions]," among, through, across, within which we move with varying amounts of ease and engagement. This flow of experience (always infused with thought and feeling, of course) could well be called "extensive" without reference yet to any specific phenomena. It is our stream of experience (to borrow from William James [1992]) in contrast to the intensive moments when we stop and think, step outside of the flow - go vertical, as it were, breaking with the horizontal to observe, judge, reflect, deal with emotions, sink into memories, analyze or otherwise turn inward. Thus do teachers sometimes, more and less purposefully, observe themselves and students interacting, but also thus do our consciences awaken and interrupt thoughtless behavior or, perhaps only apparently more trivially, thus do we interrupt any habit, banality, formalized technique when, as we say, our minds "kick in," something "catches our attention," or as I tend to say, we are startled back into thought.

Thus, in sum, do we stop and think - going from being awake, if more or less on autopilot that can carry us reliably (if not safely) far and wide, to being aware of this, here, and now such that autopilot goes off. We need to pay attention, to think for ourselves afresh. SoTL seems to me hopefully aligned with this existential grounding, stopping teaching-as-usual to pursue focused thought, bringing its fruits into ongoing exchanges with its own project to realize extensive good within education, which always has purposes more extensive than its own that are also always to be reflected on-as does SoTL, in its overarching purposes.

\section{EPILOGUE: CONNECTING SOTL, THOUGHTFULNESS, AND THE PURPOSE OF EDUCATION}

\section{JD}

As a member of ISSOTL and reader of TLI, I am interested in how SoTL might help us avoid the kind of banal thoughtlessness that can do great harm. I can imagine, for example, that we might want studies that might uncover how to avoid dangerous pitfalls, encourage better thinking, or mitigate harms. What is the SoTL study that you would most like to see done?

\section{EM}

There are many kinds of questions, many ways of
Perhaps among the most pressing of questions is this one, which cannot be answered but is important recurrently to ask: What are we living for? I think we do not in any shared way even begin to have beliefs about that. Those once available were and are tainted by unjust hierarchies; surely we do not want to revert to them. Those most available now are raw, untested, often enough tainted by a kind of materialistic and ideological superficiality unworthy of any sustainable culture.

Might we devise an education that conserves what has been while practicing us all in asking questions, listening to others, reflecting together - and coming to enjoy just that: the arts of thinking together, whatever the subject, profession, job? Might we re-invent a love of life that invites us to develop as many of our abilities as possible, to live as fully as possible?

-Elizabeth Minnich questioning, many factors that have effects on how those kinds and ways actually play out. I would like to 
see ethnographic studies of an array of classes taught by professors selected by students specifically for their artful questioning. Those studies could then be themselves studied by people looking for possible types of questioning, types that would then themselves need to be checked (and regularly rechecked) for their adequacy. Then I would like to see students completing classes in which the various types of questioning prevailed, asked to reflect about a few challenging moral situations so we could try to see if there are interesting differences in how the students think about such situations. These studies would, of course, need to give us rich material on which to reflect, not thin, tightly controlled responses. Perhaps what we'd need for these are really good interviewers, and then skilled analytical interpreters who also give readers material to check against their (or the) interpreters' work.

Complex, yes, but then, so is moral and political thinking. This is the challenge; it is also, to my mind, what is really interesting about research in this area. I'm a philosopher; I remain skeptical, and hopeful, and do look for book-length, nuanced, and descriptive, as well as analytic and honestly interpretive, studies far more than the tightly defined short-term studies that can readily be done and published in most journals.

What comes to your mind as a possible as well as really engaging research project? Help me past my skepticism?

\section{JD}

I am not so skeptical about the prospect of teaching ethical reasoning. As a moral philosopher, one of my goals is to help people become conscious consumers of the world around them. This might mean recognizing the misogyny in the lyrics of that catchy song on the radio. It might require finding ways of reminding myself of my white male privilege each time I enter a room.

In my view, ethical reasoning requires recognizing the various ways that big values (e.g., liberty, justice, personal well-being) guide our thinking. It requires understanding that those values can be in tension, and even conflict with one another, (e.g., the free exercise of hateful speech undercuts another's well-being, while restricting speech compromises freedom). And it requires understanding how those big ideas are situated in particular contexts (e.g., it is true that \#AllLivesMatter because all people are worthy of respect, but \#AllLivesMatter should not replace \#BlackLivesMatter because \#BlackLivesMatter points to the long history of systemic racism and the ramifications on people's lives). Becoming aware of conflicting values and historical circumstances helps highlight the reality that living morally or ethically often requires standing up for the values we hold most dear and this often requires making difficult choices. Careful thinking about values can lead to more thoughtful action (at least that's the hope). Because individuals don't always agree about values, careful thinking about values also involve humble listening and respectful dialogue.

As a scholar of teaching and learning I've seen the benefits of investigations into student learning and believe that the same could be done around ethical reasoning. Conducting multiple, mixed method, longitudinal studies is probably the way to go. I would focus the investigation(s) on the type of thinking and conditions that we deem most appropriate. If, for example, the goal is to uncover the various ways that biases about gender and racial identity can adversely influence our thinking, then that's a place to start. If we are hoping folks will see the conceptual connections between various big ideas (e.g., liberty, 
justice, personal well-being), then we can explore how ethical ideas are similar to, or different from, big ideas in other fields (e.g., visual art, physics, sociology, music). In short, I would welcome a book-length investigation focused on how to facilitate careful ethical thinking.

\section{CHH}

Some university leaders now speak about the need for lifelong learning and adult (re-)education, and the need to rethink the role of modern (research) universities, but some faculty members continue to reaffirm a certain (romantic?) concept of institution, an idea of the university that emphasizes learning for the sake of learning. Is there a meeting point somewhere that we can usefully define to engage faculty members in a more productive conversation about the role of the (modern) academy?

\section{EM}

Could there be such a genuine conversation, it would be a fine thing. My talk in April 2019 at the National University of Singapore, "Education for a world that works," was intended to be a response, perhaps a starting point. Simply put: there's an old dichotomy in the situation you depict that we need to surpass. It is a remnant of a class-divided society in which some could study because they need not work and others could not because they did have to. Everybody works now (more or less), and work is no longer a sign of a "lower" kind of life, mind, person. On the contrary, even: work seems now to be "higher," a mark of a superior person (some kinds of work, of course, but, nonetheless, leisure, which was the root meaning of scholar, is no longer admired). So, as we have tried to undo gender and race and ethnicity hierarchies that skewed scholarship and all else, now we need to undo the work/love of learning hierarchies in old or newer forms.

To study a field in which one may work ought to entail all the virtues of studying a field such as literature, history, or philosophy in which only some will go on to work, and vice versa. Why not? I helped develop a liberal arts major in architecture when I was a dean years ago; I can imagine a similar liberal arts major in, say, dentistry, forestry, or business. Everyone needs to learn to think in many ways; to imagine; to know history relevant to and broader than their lives and work; to ask ethical questions; to respond well to situations of sociological and psychological import. I quite love this as a challenge, but I do have to say that there has hardly been an upsurge of interest and action! That, of course, interests me even more: why not? What do we now need to re-think?

Also, or another way in: What troubles me is the notion that "engaged education" of all sorts (civic, professional, re-education, learning-work/profession connections) is antithetical to "learning for the sake of learning." Surely a richly articulated learning experience fosters a love of learning whatever its immediate purposes (or lack thereof) right along with openness to trying it out. As with physical movement, we can use our bodies to get something done-and we can enjoy the movement purely for its own sake. To submit one to the other, to choose one as if that means we have no pleasure in or responsibility for the other, seems to me a desperate mistake.

I also know that there are scholar-teachers who can articulate how studying literature, say, for the love purely of literature also practices us in arts we need to do well—to do good-in the world. Same 
for philosophy and no doubt every other field. So, I think this is a matter of good teaching, which is a matter of good human relating (as I said earlier), not either/or.

I also need to ask: What kind of a society finds it necessary to justify a love of literature, of philosophy, art, music, or history only in "practical" terms? What kind of a society assumes that working people need and want to know, to think about, to engage with only what their work requires? Do people earning a living doing something they do for pay not by free choice, not because they love it, have no other needs, rights, abilities? Are we all to be reduced to functions of whatever economic slot we fit into? (Sorry, this one really troubles me, as you can tell.)

Perhaps among the most pressing of questions is this one, which cannot be answered but is important recurrently to ask: What are we living for? I think we do not in any shared way even begin to have beliefs about that. Those once available were and are tainted by unjust hierarchies; surely we do not want to revert to them. Those most available now are raw, untested, often enough tainted by a kind of materialistic and ideological superficiality unworthy of any sustainable culture.

Might we devise an education that conserves what has been while practicing us all in asking questions, listening to others, reflecting together-and coming to enjoy just that: the arts of thinking together, whatever the subject, profession, job? Might we re-invent a love of life that invites us to develop as many of our abilities as possible, to live as fully as possible?

\section{ACKNOWLEDGMENTS}

We thank TLI editors Gary Poole and Nancy Chick for their feedback and encouragement throughout this process and their generosity in offering this journal platform for this work.

Chng Huang Hoon is Associate Professor of English Language and Literature, Associate Provost of Undergraduate Education, and Director of the Chua Thian Poh Community Leadership (entre at the National University of Singapore (SGP). She serves as copresident elect of the ISSOTL Board of Directors.

Elizabeth Minnich, philosopher, author, teacher, is a Distinguished Fellow at the Association of American Colleges and Universities (USA).

John Draeger is Professor of Philosophy and Director of the Teaching and Learning Center at University at Buffalo (USA).

Johan Geertsema is Associate Professor in the University Scholars Programme and Director of the Centre for Development of Teaching and Learning, National University of Singapore (SGP).

Torgny Roxå is Associate Professor and Academic Developer, Excellent Teaching Practitioner, Centre for Engineering Education, Faculty of Engineering at Lund University (SWE).

\section{REFERENCES}

Aristotle. (1999). Nichomachean Ethics (2nd. ed., I. Terence, trans.). Indianapolis, IN: Hackett.

Arendt, Hannah. (2003). Thinking and moral considerations. In Responsibility and judgment (J. Kohn, ed.) (pp. 159189). New York, NY: Schocken Books.

Bernstein, R. J. (1999). Praxis and action: Contemporary philosophies of human activity, Philadelphia, PA: University of Pennsylvania Press. 
Dewey, J. (1944). Democracy and education: An introduction to the philosophy of education, New York, NY: Free Press.

Dunne, J. (1993). Back to the rough ground: Practical judgment and the lure of technique. Notre Dame, IN: University of Notre Dame Press. Retrieved from https://muse.jhu.edu/book/48232

James, W. (1992). Talks to teachers on psychology and to students on some of life's ideals. In G. E. Myers (Ed.), William James: Writings, 1878-1899 (pp. 715-721). New York, NY: Library of America.

Jaspers, K. (1947). The question of German guilt (E. B. Ashton, Trans.). New York, NY: Dial Press.

May, S. \& Sleeter, C. E. (Eds.) (2010). Critical multiculturalism: Theory and praxis. New York, NY: Routledge.

Minnich, E. (2005). Transforming knowledge (2nd ed.). Philadelphia, PA: Temple University Press

Minnich, E. K. (2010). Teaching thinking: Moral and political considerations. Change: The Magazine of Higher Learning, 35(5), 18-24. https://doi.org/10.1080/00091380309604115

Minnich, E. (2017). The evil of banality: On the life and death importance of thinking. Lanham, MD: Rowman \& Littlefield.

Minnich, E. K. (2018, October). People who are not thinking are capable of anything: What are students learning, how are students learning it, and does it make them better people? Keynote presentation at the International Society for the Scholarship of Teaching and Learning, Bergen, Norway.

Minnich, E. K. (2019, April). Educating for a world of work. Presentation at the National University of Singapore.

Minnich, E. K., Gardner, L. \& Sorkin, B. (2016). In the presence of teaching: Reflections from a project. Change: The Magazine of Higher Learning, 48(3), 60-66. https://doi.org/10.1080/00091383.2016.1170554

Minnich, E. K., Sorkin, B., \& Gardner, L. (2016). Present teaching: We are creating the future now and reflections from a project on thinking what we are doing. In M. Ford and S. Rowe (Eds.), Educating for an ecological civilization: Interdisciplinary, experiential, and relational learning (pp. 105-126). Anoka, MN: Process Century Press.

Minnich, E., \& Patton, M. Q. (Eds.) (in press). Thought work: Thinking, action, and the fate of the world. Lanham, MD: Rowman \& Littlefield.

Moorehead, C. (2015). Village of secrets: Defying the Nazis in Vichy France. New York, NY: Harper Perennial.

Patton, M. Q. (2008). The paradigms debate. In Utilization-focused evaluation (4th ed.) (pp. 419-470). Thousand Oaks, CA: Sage).

Patton, M. Q. (2014). Week 47: Fools' gold: The widely touted methodological "gold standard" is neither golden nor a standard. [Web log post]. Retrieved from

https://www.betterevaluation.org/en/blog/fools gold widely touted methodological gold standard

Patton, M. Q. (2015). Qualitative research and evaluation methods (4th ed). Thousand Oaks, CA: Sage.

Roxå, T. (2018, October). A learning culture: More about how than about what. Keynote presentation at the International Society for the Scholarship of Teaching and Learning, Bergen, Norway.

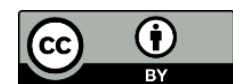

Copyright for the content of articles published in Teaching \& Learning Inquiry resides with the authors, and copyright for the publication layout resides with the journal. These copyright holders have agreed that this article should be available on open access under a Creative Commons Attribution License 4.0 International (https://creativecommons.org/licenses/by/4.0). The only constraint on reproduction and distribution, and the only role for copyright in this domain, should be to give authors control over the integrity of their work and the right to be properly acknowledged and cited, and to cite Teaching \& Learning Inquiry as the original place of publication. Readers are free to share these materials - as long as appropriate credit is given, a link to the license is provided, and any changes are indicated. 